\title{
Genetic assessment of BoLA-DRB3 polymorphisms by comparing Bangladesh, Ethiopian, and Korean cattle
}

\author{
Ayele Mandefro ${ }^{1}$, Tesfaye Sisay ${ }^{2}, Z^{2}$ ewdu Edea ${ }^{3}$, Md. Rasel Uzzaman ${ }^{3}$, \\ Kwan-Suk Kim ${ }^{3 *}$ and Hailu Dadi ${ }^{4 *}$ \\ ${ }^{1}$ Department of Biotechnology, Addis Ababa Science and Technology University, Addis Ababa 16417, Ethiopia \\ ${ }^{2}$ Institute of Biotechnology, Addis Ababa University, Addis Ababa 1176, Ethiopia \\ ${ }^{3}$ Department of Animal Science, Chungbuk National University, Cheongju 28644, Korea \\ ${ }^{4}$ Ethiopian Biotechnology Institute, Addis Ababa 5954, Ethiopia
}

Received: Nov 26, 2020

Revised: Jan 3, 2021

Accepted: Jan 10, 2021

${ }^{*}$ Corresponding author Kwan-Suk Kim

Department of Animal Science, Chungbuk National University, Cheongju 28644, Korea.

Tel: +82-70-8257-2547

E-mail: kwanskim@chungbuk.ac.kr

Hailu Dadi

Ethiopian Biotechnology Institute, Addis Ababa 5954, Ethiopia.

Tel: +251-911210539

E-mail: edenhailu@yahoo.com

Copyright $\odot 2021$ Korean Society of Animal Sciences and Technology. This is an Open Access article distributed under the terms of the Creative Commons Attribution Non-Commercial License (http:// creativecommons.org/licenses/by$\mathrm{nc} / 4.0 /$ ) which permits unrestricted non-commercial use, distribution, and reproduction in any medium, provided the original work is properly cited.

ORCID

Ayele Mandefro

https://orcid.org/0000-0003-0778-6723

Tesfaye Sisay

https://orcid.org/0000-0002-4103-5029

Zewdu Edea

https://orcid.org/0000-0003-2343-4832

Md. Rasel Uzzaman

https://orcid.org/0000-0002-3525-4794

Kwan-Suk Kim

https://orcid.org/0000-0002-5895-4398

\section{Abstract}

Attributable to their major function in pathogen recognition, the use of bovine leukocyte antigens (BoLA) as disease markers in immunological traits in cattle is well established. However, limited report exists on polymorphism of the BoLA gene in zebu cattle breeds by high resolution typing methods. Thus, we used a polymerase chain reaction sequence-based typing (PCR-SBT) method to sequence exon 2 of the BoLA class II DRB3 gene from 100 animals (Boran, $n=13$; Sheko, $n=20$; Fogera, $n=16$; Horro, $n=19)$, Hanwoo cattle $(n=18)$ and Bangladesh Red Chittagong zebu $(n=14)$. Out of the 59 detected alleles, 43 were already deposited under the Immuno Polymorphism Database for major histocompatibility complex (IPD-MHC) while 16 were unique to this study. Assessment of the level of genetic variability at the population and sequence levels with genetic distance in the breeds considered in this study showed that Zebu breeds had a gene diversity score greater than 0.752 , nucleotide diversity score greater than 0.152 , and mean number of pairwise differences higher than 14 , being very comparable to those investigated for other cattle breeds. Regarding neutrality tests analyzed, we investigated that all the breeds except Hanwoo had an excess number of alleles and could be expected from a recent population expansion or genetic hitchhiking. Howbeit, the observed heterozygosity was not significantly $(p<0.05)$ higher than the expected heterozygosity. The Hardy Weinberg equilibrium (HWE) analysis revealed non-significant excess of heterozygote animals, indicative of plausible over-dominant selection. The pairwise FST values suggested a low genetic variation among all the breeds (FST $=0.056 ; p<0.05$ ), besides the rooting from the evolutionary or domestication history of the cattle. No detached clade was observed in the evolutionary divergence study of the BoLA-DRB3 gene, inferred from the phylogenetic tree based on the maximum likelihood model. The investigation herein indicated the clear differences in BoLA-DRB3 gene variability between African and Asian cattle breeds.

Keywords: BoLA-DRB3, Cattle breeds, Sequence based typing (SBT), Genetic diversity, Alleles 
Hailu Dadi

https://orcid.org/0000-0001-8918-4544

Competing interests

No potential conflict of interest relevant to

this article was reported.

Funding sources

We acknowledge the Ethiopian Ministry of Innovation and Technology for funding the data collection process from different parts of Ethiopia. Sequencing and international travel expenses were also supported by grants from National Research Foundation of Korea (Nos. NRF-2017R1A2B1008883 and 2020R1A4A1017552).

Acknowledgements

Not applicable.

Availability of data and material Upon reasonable request, the datasets of this study can be available from the corresponding author.

Authors' contributions

Conceptualization: Kim KS, Dadi H.

Data curation: Mandefro A, Dadi $\mathrm{H}$.

Formal Analysis: Mandefro A

Methodology: Mandefro A, Sisay T, Dadi H, Kim KS.

Software: Mandefro A, Edea Z, Uzzaman MR.

Writing original draft: Mandefro A, Sisay T, Dadi $\mathrm{H}$.

Writing-editing: Mandefro A, Sisay T, Edea Z, Uzzaman MR, Kim KS, Dadi H.

Ethics approval and consent to participate This article does not require IRB/IACUC approval because there are no human and animal participants.

\section{INTRODUCTION}

Major histocompatibility complex (MHC) is a group of closely linked genes that forms a dynamic genetic component of the mammalian immune system. Bovine $\mathrm{MHC}$ isolation and characterization were determined long years ago [1-3]. MHC molecule is the primary component of adaptive immunity in bovines and the two classes of MHC genes (class I and class II) are the main gears of the $\mathrm{MHC}$ region; typically the most polymorphic regions of the gene in the majority of the mammalian genome [4]. MHC molecule is physically mapped on the bovine autosome 23 (BTA 23). The MHC of cattle is called bovine leukocyte antigen (BoLA), which is highly variable and helpful in the immune systems. The role of BoLA in cattle is to recognize pathogens via the immune systems and mainly used as a disease marker in cattle breeding programs $[4,5]$.

BoLA-DRB3 locus is the most widely studied and polymorphic region in bovines. The allele diversity and polymorphisms of the DRB3 gene in cattle breeds have recently been reported by sequence-based typing [6]. According to the report available in immuno-polymorphism database (IPD-data base) 136 alleles are deposited so far; by which such impressive polymorphisms have resided on the $\beta 1$ domains of the peptide-binding regions (PBR) [7,8]. Among the six exons of BoLA-DRB3 gene, exon 2 has previously been reported to be the most polymorphic and potentially affect many immunities, somatic cell count and mastitis incidence [9]. Moreover, recent studies reported that the BoLA DRB3 gene has been associated with susceptibility or resistance to mastitis [10,11].

Polymorphisms of BoLA-DRB3.2 in Korean cattle and Holstein cattle were characterized using a next generation sequencer [12] and aimed at the identification of molecular markers linked to bovine diseases and immunological traits by comparing other unique cattle breeds from developing countries like Bangladesh and Ethiopia.

Red Chittagong $(\mathrm{RC})$ is one of the promising cattle varieties of Bangladesh. They are well adapted to traditional husbandry practices, subsistence on poor quality feeds and fodders. They have been breeding regularity and better resistance capabilities to withstand environmental stress and tropical diseases [13]. Yet, the BoLA DRB3.2 gene has not been studied in the RC cattle breed.

Ethiopia harbors diverse cattle populations adapted to a range of harsh environments. Sheko cattle are well adapted to humid environments of south-western Ethiopia characterized by high tsetse fly infestation [14]. In contrast, cattle populations such as Boran, Ogaden, and Afar have long been evolved under arid and semi-arid areas of eastern and southern Ethiopia where the risk of trypanosomiasis is relatively low. Despite some differences in their response to local diseases and parasites, to the best of our knowledge, no study has been made to characterize the MHC BoLA DRB3.2 gene in Bangladesh and Ethiopian cattle breeds which are critically important for future breeding programs. The aim of this study was, therefore, to characterize the genetic variability of DRB3.2 in the African and Asian zebu and taurine cattle breeds.

\section{MATERIALS AND METHODS}

\section{Study cattle breeds and DNA extraction}

A total of 100 animals comprising of four Ethiopian indigenous cattle (Boran, $n=13$; Sheko, $n=$ 20; Fogera, $n=16$; Horro, $n=19)$, Korean Hanwoo cattle $(n=18)$ and Bangladesh Red Chittagong zebu $(n=14)$ were considered in this study (Table 1$)$. These samples were randomly selected from multiple herds and 102 additional Holstein Freisian sequence samples were downloaded from the National Center for Biotechnology Information (NCBI), included in the analysis.

Nasal swabs were collected using an Animal Swabs Collector (BlueGene Life Science, 
Table 1. Detail descriptions of the sampled cattle breeds

\begin{tabular}{lcccccc}
\hline Acronym & $\begin{array}{c}\text { Sample } \\
\text { size }\end{array}$ & Number of farms & Breed & Type & $\begin{array}{c}\text { Country of } \\
\text { origin }\end{array}$ & $\begin{array}{c}\text { Sampling } \\
\text { country }\end{array}$ \\
\hline RC & 14 & Randomly collected & Red Chittagong & Zebu & & Bangladesh \\
BO & 13 & 1 & Boran & Zebu & & Ethiopia \\
FO & 16 & 1 & Fogera & Zebu & Ethiopia & Ethiopia \\
HN & 18 & Randomly collected & Hanwoo & Zebu $\times$ Taurine & Korea & Korea \\
HO & 19 & Randomly collected & Horro & Zebu & Ethiopia & Ethiopia \\
SH & 20 & Randomly collected & Sheko & Zebu $\times$ Taurine & Ethiopia & Ethiopia \\
\hline
\end{tabular}

Cheongju, Korea) and Performagene LIVESTOCK's nasal swabs (DNA Genotek, Kanata, ON, Canada). DNA was isolated from nasal swabs following the manufacturer's instructions.

The quality of the DNA and its concentration were quantified via NanoDrop1000 and electrophoresis in $0.8 \%$ agarose gels. Those DNA samples with good quality and quantity were considered for amplification and sequencing.

\section{Polymerase chain reaction (PCR) amplification of BoLA-DRB3.2 region}

To amplify exon2 of the BoLA-DRB3 gene, we used primers reported in the previous study [15]. PCR technique amplified 284 bp product at the second exonic region. The reactions were carried out in a total volume of $30 \mu \mathrm{L}$ containing genomic DNA $(2 \mu \mathrm{L}$ of $50 \mathrm{ng} / \mu \mathrm{L}), 21.1 \mu \mathrm{L}$ distilled water, $10 \times$ PCR buffer $(3 \mu \mathrm{L}), 10 \mathrm{mM}$ dNTPs $(0.6 \mu \mathrm{L})$, forward and reverse primers $(1.5 \mu \mathrm{L}$ of 10 $\mathrm{pM}$ for each), and $0.3 \mu \mathrm{L}$ of Taq DNA polymerase (Promega, San Diego, CA, USA).

Reactions were performed; at 35 cycles of $94^{\circ} \mathrm{C}$ for $30 \mathrm{~s}$, annealing at $60^{\circ} \mathrm{C}$ for $30 \mathrm{~s}$, and $72^{\circ} \mathrm{C}$ for $40 \mathrm{~s}$ preceded by initial denaturation at $94^{\circ} \mathrm{C}$ for $10 \mathrm{~min}$ and a final extension at $72^{\circ} \mathrm{C}$ for 5 min. Finally, the PCR products were visualized by gel electrophoresis on $2 \%$ agarose gels with acetate EDTA (TAE) buffer followed by ethidium bromide staining. Sequencing was performed by Macrogen (Seoul, Korea).

\section{BoLA-DRB3 typing via Sequence based typing (SBT) and statistical analysis}

We conducted PCR-SBT technique to evaluate the genetic variability of BoLA-DRB3.2 gene. The study was pioneered for characterization of the BoLA DRB3.2 region in the Ethiopian cattle breeds. Polymorphism of the BoLA-DRB3.2 region was investigated in four Ethiopian local breeds (Boran, Fogera, Horro, and Sheko) and Korean Hanwoo and Bangladesh Red Chittagong. The DNA sequences were edited using Bio-edit version 7.0.5.3 and aligned by clustalX2 software package [16]. DNA polymorphism was computed based on six parameters (number of polymorphic sites, the total number of mutations, the average number of nucleotide differences, number of haplotypes, haplotype diversity and nucleotide diversity) using ARLEQUIN software version 3.5.2.2 [17]. Also, the allele frequencies and number of alleles were estimated by the same software. The deviations from Hardy Weinberg equilibrium (HWE) were computed by F-statistics [18]. Moreover, observed and unbiased expected heterozygosity was calculated by ARLEQUIN and GENPOP4.0 software [19]. Pattern of sequence variability, synonymous and non-synonymous substitutions were computed by DnaSP version 6.12.03 software [20]. Nucleotide similarities of the newly identified alleles with the reference sequence (BoLA-DRB3:016:01) were generated by the sequence demarcation tool [21]. The average haplotype count per individual (AHC) was calculated by dividing the number of haplotypes by the number of animals considered [22]. 


\section{Population differentiation and neutrality tests}

Population differentiation due to the population genetic structure was also assessed from sequence data, population pairwise Wright's $\mathrm{F}_{\mathrm{ST}}$ [18] values were calculated by using ARLEQUIN software version 3.5.2.2 applying 1000 replication values [17]. The pairwise $\mathrm{F}_{\mathrm{ST}}$ graph was displayed by Rcmd (console version of the $\mathrm{R}$ statistical package) installed on the computer integrated with ARLEQUIN (http://www.r-project.org/). Moreover, population genetic differentiations based on the BoLA-DRB3 gene of the breeds were evaluated by Ne's genetic distance $\left(\mathrm{G}_{\mathrm{ST}}\right)$ by DnaSP software. Molecular diversity index statistics, the number of transitions and numbers of transversions were computed by ARLEQUIN software version 3.5.2.2 [17].

Neutrality tests were performed by infinite site model using ARLEQUIN software. Tajima's $\mathrm{D}$ and Fu's Fs neutrality tests were estimated based on the mean number of pairwise differences between haplotypes and probability of observing an average number of nucleotides (number of alleles), respectively [23,24].

\section{Phylogenetic relationships and Median joining network}

Phylogenetic analysis was carried out using the Maximum Likelihood method based on the Kimura 2-parameter model [25] using MEGAX 10.1 software [26] via implementing1000 bootstrap values [27]. Positions from DNA sequences containing gaps or missing data including identical sequences were excluded from the analysis.

Median-joining network (MJN) tree was constructed using the NETWORK software (version 10.0.0) [28]. To evaluate the median network, the nucleotide sequences were first converted into binary data, while identical sites were omitted from the analysis. Each split was programmed as a binary character, satisfying the values of 0 and 1 . The haplotypes were denoted as a binary vector in this method. The median vectors were estimated for each triplet of vectors until the construction of the median network was achieved [28].

\section{RESULTS}

Allele distribution of MHC class II BoLA-DRB3.2 in the analyzed cattle breeds PCR-SBT analysis of BoLA-DRB3.2 resulted in the identification of 59 BoLA-DRB3.2 alleles of which 16 alleles (BoLA-DRB3*164:01, BoLA-DRB3*165:01, BoLA-DRB3*166:01, BoLADRB3*167:01, BoLA-DRB3*168:01, BoLA-DRB3*169:01, BoLA-DRB3*170:01, BoLADRB3*171:01, BoLA-DRB3*172:01, BoLA-DRB3*173:01, BoLA-DRB3*174:01, BoLADRB3*175:01, BoLA-DRB3*176:01, BoLA-DRB3*177:01, BoLA-DRB3*178:01 and BoLADRB3*179:01) were reported here for the first time. All sequences were deposited in the NCBI gene bank data base with accession numbers MT919537-MT919549 (Bangladesh), MT919550MT919562 (Boran), MT919563-MT919578 (Fogera), MT919579-MT919596 (Hanwoo), MT919597-MT919615 (Horro), and MT919616-MT919637 (Sheko). Among 59 different alleles, 11 alleles in Bangladesh Red Chittagong, 12 in Boran, 13 in Fogera, 8 in Korean Hanwoo, 14 in Horro and 18 in Sheko were detected. Alleles were named temporarily based on the principles of IPD-MHC database.

The allele BoLA-DRB3*145:01 shared between the Bangladesh Red Chittagong and two Ethiopian breeds (Boran and Horro). The allele BoLA-DRB3*100:01 was recorded only in three Ethiopian breeds (Boran, Fogera, and Horro). The Korean Hanwoo breed shared BoLADRB3*021:01 allele with three Ethiopian breeds (Fogera, Horro, and Sheko). However, no alleles were shared between Korean Hanwoo and Bangladesh Red Chittagong. Moreover, BoLADRB3*002:01 allele had a higher frequency of 0.444 while the lowest frequency was 0.050 which 
was observed for many alleles (Table 2).

Genetic diversity analysis of BoLA-DRB3.2 gene in the analyzed cattle breeds The nucleotide sequences of the newly identified alleles were compared with the reference sequence from the IPD-MHC data base (BoLA-DRB3*106: 01) and higher variability of the region was visualized (Fig. 1). The nucleotide identity of the new alleles identified from this study compared to the reference sequence from IPD-MHC data base showed 88\%-100\% similarity (Fig. 2).

The number of polymorphic sites (S) which is the measure of usable loci that show more than one allele per locus was analyzed. The value of S was higher in Sheko (65) and lower in Hanwoo (47). Bangladesh Red Chittagong and Ethiopian Fogera had the same number of polymorphic sites (53). The nucleotide diversities (П) were relatively high in Boran breeds $(0.072)$ whereas in the Korean Hanwoo breed a relatively low number of $\Pi(0.056)$ was observed. For all breeds,

Table 2. Comparison of the allele distributions and frequencies of BoLA-DRB3.2 sequences among considered breeds

\begin{tabular}{|c|c|c|c|c|c|c|}
\hline Alleles & RC & BO & FO & $\mathrm{HN}$ & $\mathrm{HO}$ & SH \\
\hline BoLA-DRB3*145:01 & 0.071 & 0.077 & - & - & 0.053 & - \\
\hline BoLA-DRB3*120:01 & 0.071 & - & - & - & - & - \\
\hline BoLA-DRB3*157:01 & 0.071 & - & - & - & - & - \\
\hline BoLA-DRB3*112:01 & 0.286 & - & - & - & - & 0.050 \\
\hline BoLA-DRB3*164:01 & 0.143 & - & - & - & - & - \\
\hline BoLA-DRB3*032:01 & 0.071 & - & - & - & - & 0.050 \\
\hline BoLA-DRB3*165:01 & 0.071 & - & - & - & - & - \\
\hline BoLA-DRB3*166:01 & 0.071 & - & - & - & - & - \\
\hline BoLA-DRB3*167:01 & 0.071 & - & - & - & - & - \\
\hline BoLA-DRB3*018:01 & 0.071 & - & - & - & - & - \\
\hline BoLA-DRB3*020:12 & - & 0.077 & - & - & - & - \\
\hline BoLA-DRB3*168:01 & - & 0.077 & - & - & - & - \\
\hline BoLA-DRB3*169:01 & - & 0.077 & - & - & - & - \\
\hline BoLA-DRB3*135:01 & - & 0.077 & - & - & - & - \\
\hline BoLA-DRB3*112:01 & - & 0.077 & - & - & - & - \\
\hline BoLA-DRB3*170:01 & - & 0.154 & - & - & - & - \\
\hline BoLA-DRB3*020:08 & - & 0.077 & - & 0.056 & - & - \\
\hline BoLA-DRB3*100:01 & - & 0.077 & 0.063 & - & 0.158 & - \\
\hline BoLA-DRB3*007:01 & - & 0.077 & - & - & - & - \\
\hline BoLA-DRB3*011:01 & - & 0.077 & - & 0.056 & - & - \\
\hline BoLA-DRB3*171:01 & - & 0.077 & - & - & - & - \\
\hline BoLA-DRB3*087:03 & - & - & 0.188 & - & - & - \\
\hline BoLA-DRB3*021:01 & - & - & 0.062 & 0.111 & 0.053 & 0.150 \\
\hline BoLA-DRB3*172:01 & - & - & 0.062 & - & - & - \\
\hline BoLA-DRB3*093:01 & - & - & 0.062 & - & - & - \\
\hline BoLA-DRB3*145:01 & - & - & 0.062 & - & - & - \\
\hline BoLA-DRB3*137:01 & - & - & 0.062 & - & - & - \\
\hline BoLA-DRB3*130:01 & - & - & 0.062 & 0.056 & - & - \\
\hline BoLA-DRB3*008:02 & - & - & 0.062 & - & 0.053 & - \\
\hline BoLA-DRB3*044:01 & - & - & 0.062 & - & - & - \\
\hline BoLA-DRB3*007:03 & - & - & 0.062 & - & - & 0.050 \\
\hline
\end{tabular}


Table 2. Continued

\begin{tabular}{|c|c|c|c|c|c|c|}
\hline Alleles & RC & BO & FO & HN & HO & SH \\
\hline BoLA-DRB3*173:01 & - & - & 0.062 & - & - & - \\
\hline BoLA-DRB3*015:04 & - & - & 0.062 & - & - & - \\
\hline BoLA-DRB3*122:01 & - & - & 0.062 & - & - & - \\
\hline BoLA-DRB3*009:02 & - & - & - & 0.111 & - & - \\
\hline BoLA-DRB3*002:01 & - & - & - & 0.444 & - & - \\
\hline BoLA-DRB3*020:08 & - & - & - & 0.056 & - & - \\
\hline BoLA-DRB3*013:03 & - & - & - & 0.056 & - & - \\
\hline BoLA-DRB3*174:01 & - & - & - & 0.056 & - & - \\
\hline BoLA-DRB3*024:12 & - & - & - & - & 0.105 & - \\
\hline BoLA-DRB3*032:03 & - & - & - & - & 0.105 & 0.100 \\
\hline BoLA-DRB3*123:01 & - & - & - & - & 0.105 & - \\
\hline BoLA-DRB3*086:04 & - & - & - & - & 0.053 & - \\
\hline BoLA-DRB3*100:02 & - & - & - & - & 0.053 & - \\
\hline BoLA-DRB3*094:02 & - & - & - & - & 0.053 & - \\
\hline BoLA-DRB3*107:03 & - & - & - & - & 0.053 & 0.100 \\
\hline BoLA-DRB3*104:01 & - & - & - & - & 0.053 & - \\
\hline BoLA-DRB3*028:03 & - & - & - & - & 0.053 & - \\
\hline BoLA-DRB3*175:01 & - & - & - & - & - & 0.050 \\
\hline BoLA-DRB3*141:01 & - & - & - & - & - & 0.050 \\
\hline BoLA-DRB3*007:02 & - & - & - & - & - & 0.050 \\
\hline BoLA-DRB3*010:03 & - & - & - & - & - & 0.050 \\
\hline BoLA-DRB3*176:01 & - & - & - & - & - & 0.050 \\
\hline BoLA-DRB3*177:01 & - & - & - & - & - & 0.050 \\
\hline BoLA-DRB3*178:01 & - & - & - & - & - & 0.050 \\
\hline BoLA-DRB3*107:01 & - & - & - & - & - & 0.050 \\
\hline BoLA-DRB3*013:04 & - & - & - & - & - & 0.050 \\
\hline BoLA-DRB3*027:08 & - & - & - & - & - & 0.050 \\
\hline BoLA-DRB3*179:01 & - & - & - & - & 0.053 & - \\
\hline
\end{tabular}

${ }^{*}$ Alleles written in bold indicated that the new alleles identified in the current study and not reported in IPD-MCH database. BoLA, bovine leukocyte antigens; RC, Red Chittagong; Bo, Boran; Fo, Fogera; HN, Korean Hanwoo; HO, Horro; SH, Sheko; IPD-MHC, Immuno Polymorphism Database for major histocompatibility complex.

synonymous substitutions were less as compared to the non-synonymous substitutions (Table 3). Haplotypes were constructed for each breed and a total of 59 haplotypes were obtained. Of the six cattle breeds, the haplotype values ranged from 18 (Sheko) to 8 (Korean Hanwoo). The haplotype diversity (Hd) of the Ethiopian breeds and Bangladesh Red Chittagong were relatively higher as compared to the Korean Hanwoo. The haplotype diversity for Korean Hanwoo was 0.751 which was the lowest as compared to the rest of the breed. The average number of haplotype count per animal varied from 0.500 in Hanwoo to 0.846 in Ethiopian Boran. The AHC for Sheko was higher next to Boran (0.800). The average numbers of nucleotide differences (NPD) were highest in Boran (18.307) and lowest in Hanwoo (14.339). Moreover, the ratio of non-synonymous substitution (NSs) to synonymous substitution (SS) was highest in Sheko with an estimated value of 3.300 and lowest in Korean Hanwoo with an estimated value of 1.500 (Table 3). 

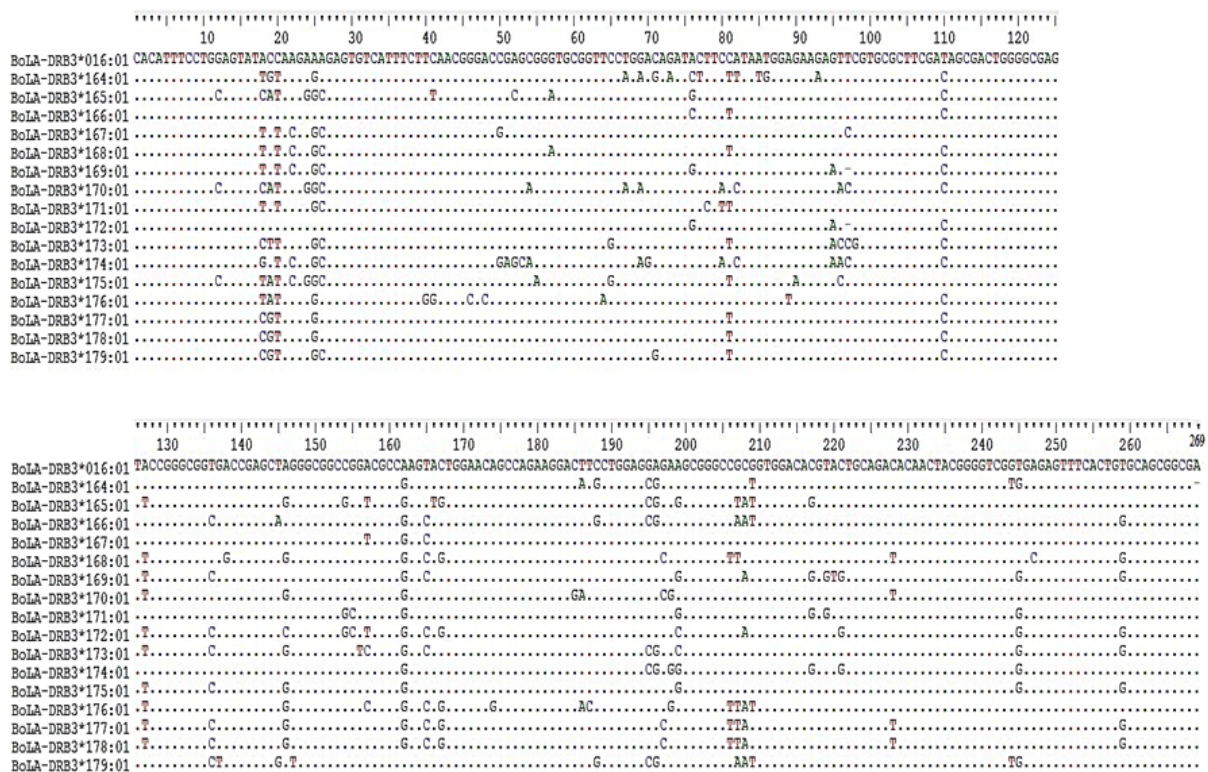

Fig. 1. The nucleotide sequences of the newly identified alleles were compared with the reference sequence from the IPD-MHC data base (BoLA-DRB3*106:01) and higher variability of the region was visualized. IPD-MHCl, mmuno Polymorphism Database for major histocompatibility complex; BoLA, bovine leukocyte antigens.

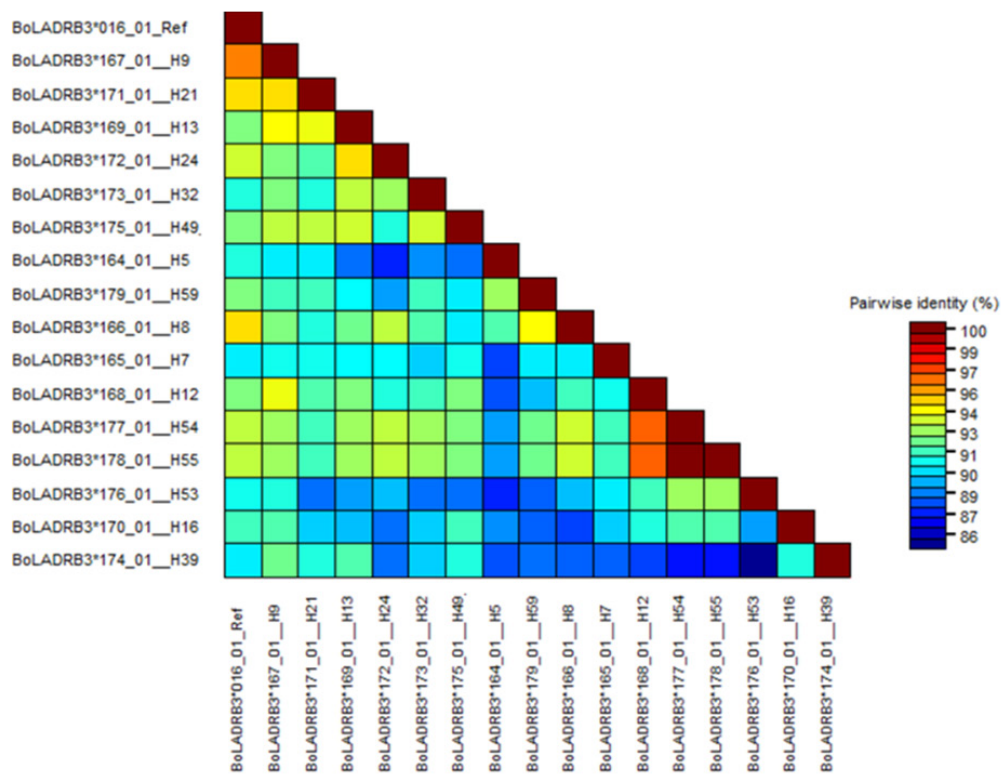

Fig. 2. The nucleotide identity of the new alleles identified from this study compared to the reference sequence from IPD-MHC data base showed $88 \%-100 \%$ similarity. IPD-MHCl, Immuno Polymorphism Database for major histocompatibility complex.

Genetic diversity, HWE and neutrality tests of BoLA-DRB3.2 gene in cattle breeds from different geographic locations

To understand genetic diversity within a population, the mean number of alleles per locus $(\mathrm{Na})$, the average expected $(\mathrm{He})$ and observed heterozygosity $(\mathrm{Ho})$ values, $\mathrm{HWE}$ in terms of $\mathrm{F}_{\text {IS }}$ coefficient and neutrality tests were estimated. Hence, in Korean Hanwoo the lowest number of alleles (8) 
Table 3. DNA polymorphism of BoLA-DRB3.2, nucleotide diversity $(\pi)$, mean number of nucleotide differences (NPD), number of polymorphic sites (S), haplotype number (H), haplotype diversity (Hd), average haplotype count (AHC), synonymous (SS) and non-synonymous (NSS) substitutions with estimated ratios for considered breeds

\begin{tabular}{lccccccccc}
\hline Breeds & $\pi$ & NPD & S & H & Hd & AHC & SS & NSS & NSs/Ss ratio \\
\hline RC & 0.063 & 16.186 & 53 & 11 & 0.934 & 0.714 & 13 & 24 & 1.850 \\
BO & 0.072 & 18.307 & 54 & 12 & 0.987 & 0.846 & 11 & 27 & 2.450 \\
FO & 0.068 & 17.292 & 53 & 13 & 0.966 & 0.625 & 13 & 21 & 1.610 \\
HN & 0.056 & 14.339 & 47 & 8 & 0.751 & 0.500 & 16 & 24 & 1.500 \\
HO & 0.064 & 16.380 & 58 & 14 & 0.964 & 0.736 & 11 & 23 & 2.090 \\
SH & 0.065 & 16.631 & 65 & 18 & 0.989 & 0.800 & 10 & 33 & 3.300 \\
\hline
\end{tabular}

BoLA, bovine leukocyte antigens; RC, Red Chittagong; Bo, Boran; Fo, Fogera; HN, Korean Hanwoo; HO, Horro; SH, Sheko.

was observed, whereas in Sheko the highest numbers of alleles (18) were detected. The observed heterozygosity (Ho) ranged between 0.750 in Fogera to 0.980 in Ethiopian Boran (Table 4). The expected heterozygosity (He) was ranged from 0.804 (Hanwoo) to 0.987 (Boran). Moreover, we recorded the following values of He from Red Chittagong (0.923), Fogera (0.975), Horro (0.965), and Sheko (0.979).

The Tajima's D value obtained was negative in three breeds (Bangladesh, Horro, and Sheko), but Tajima's D value in Boran, Fogera, and Hanwoo were $0.233,0.350$, and 0.203 , respectively. Except for Korean Hanwoo breed which had Fu's Fs recorded value of 4.594 all remaining breeds had a negative estimated value of Fs. Fu's Fs p-values was highest in Hanwoo (0.959) breed and lowest in Sheko (0.052). Concerning the values of Hardy Weinberg equilibrium (HWE), all the breeds showed a significant deviation from the theoretical hypothesis (we estimated significant excess of homozygotes) (Table 5).

\section{Genetic structure and population differentiation of BoLA-DRB3 gene among the cattle breeds}

We estimated two main parameters ( $\mathrm{F}_{\mathrm{ST}}$ index and exact $\mathrm{G}$ test $)$ for the inspection of population genetic structure and differentiation levels among cattle breeds. The $\mathrm{F}_{\mathrm{ST}}$ parameters showed significant differences across all cattle breeds $\left(\mathrm{F}_{\mathrm{ST}}=0.056 ; p\right.$-value $\left.\leq 0.0001\right)$; pairwise comparisons ranged from -0.003 (between Boran and Sheko) to 0.164 (Hanwoo with Horro and Sheko) (Table 5). The calculated $\mathrm{F}_{\mathrm{ST}}$ values between population pairs were also graphically represented by using $\mathrm{R}$-statistics (Fig. 3). The negative $\mathrm{F}_{\mathrm{ST}}$ values recorded between Sheko and Boran as well as between Sheko and Fogera indicated that no genetic subdivision between these populations. The exact $\mathrm{G}$ test

Table 4. Number of sequences $(\mathrm{N})$, number of alleles $(\mathrm{Na})$, observed $(\mathrm{Ho})$ and expected heterozygosity $(\mathrm{He})$ and Fu's Fs and Tajima's D neutrality test statistics and Hardy Weinberg equilibrium (HWE) in terms of $F_{\text {IS }}$ coefficient

\begin{tabular}{|c|c|c|c|c|c|c|c|c|c|}
\hline Breed & $\mathbf{N}$ & $\mathrm{Na}$ & Ho & $\mathrm{He}$ & $\underset{p \text {-value }}{F_{\text {Is }^{-}}}$ & Fu's Fs & $\begin{array}{c}\text { Fs } \\
p \text {-value }\end{array}$ & $\underset{\text { D }}{\text { Tajima's }}$ & $\begin{array}{l}\text { Tajima's } \\
p \text {-value }\end{array}$ \\
\hline $\mathrm{RC}$ & 14 & 11 & 0.920 & 0.923 & 0.082 & -0.116 & 0.439 & -0.126 & 0.458 \\
\hline $\mathrm{BO}$ & 13 & 12 & 0.980 & 0.987 & 0.053 & -1.699 & 0.164 & 0.233 & 0.630 \\
\hline $\mathrm{FO}$ & 16 & 13 & 0.750 & 0.975 & 0.066 & -0.841 & 0.318 & 0.350 & 0.695 \\
\hline $\mathrm{HN}$ & 18 & 8 & 0.800 & 0.804 & 0.081 & 4.594 & 0.959 & 0.203 & 0.612 \\
\hline $\mathrm{HO}$ & 19 & 14 & 0.960 & 0.965 & 0.055 & -0.478 & 0.424 & -0.052 & 0.516 \\
\hline $\mathrm{SH}$ & 20 & 18 & 0.970 & 0.979 & 0.055 & -4.219 & 0.052 & -0.374 & 0.376 \\
\hline
\end{tabular}


Table 5. Genetic distances between pairs of populations based on Wright's F-statistics $\mathbf{F}_{\mathrm{ST}}$ below the diagonal and Nei's genetic distance $\mathrm{G}_{\mathrm{ST}}$ above the diagonal estimated.

\begin{tabular}{lccccccc}
\hline Breed & HF & RC & BO & FO & HN & HO & SH \\
\hline HF & - & 0.019 & 0.010 & 0.010 & 0.050 & 0.008 & 0.006 \\
RC & 0.029 & - & 0.017 & 0.023 & 0.086 & 0.024 & 0.110 \\
BO & 0.012 & 0.015 & - & 0.007 & 0.064 & 0.005 & 0.007 \\
FO & 0.036 & 0.020 & 0.020 & - & 0.074 & 0.008 & 0.005 \\
HN & 0.084 & 0.137 & 0.092 & 0.151 & - & 0.074 & 0.067 \\
HO & 0.029 & 0.019 & 0.005 & 0.036 & 0.164 & - & 0.008 \\
SH & 0.029 & 0.007 & -0.003 & -0.015 & 0.164 & 0.001 & - \\
\hline
\end{tabular}

HF, Holstein-Friesian; RC, Red Chittagong; Bo, Boran; Fo, Fogera; HN, Korean Hanwoo; HO, Horro; SH, Sheko.

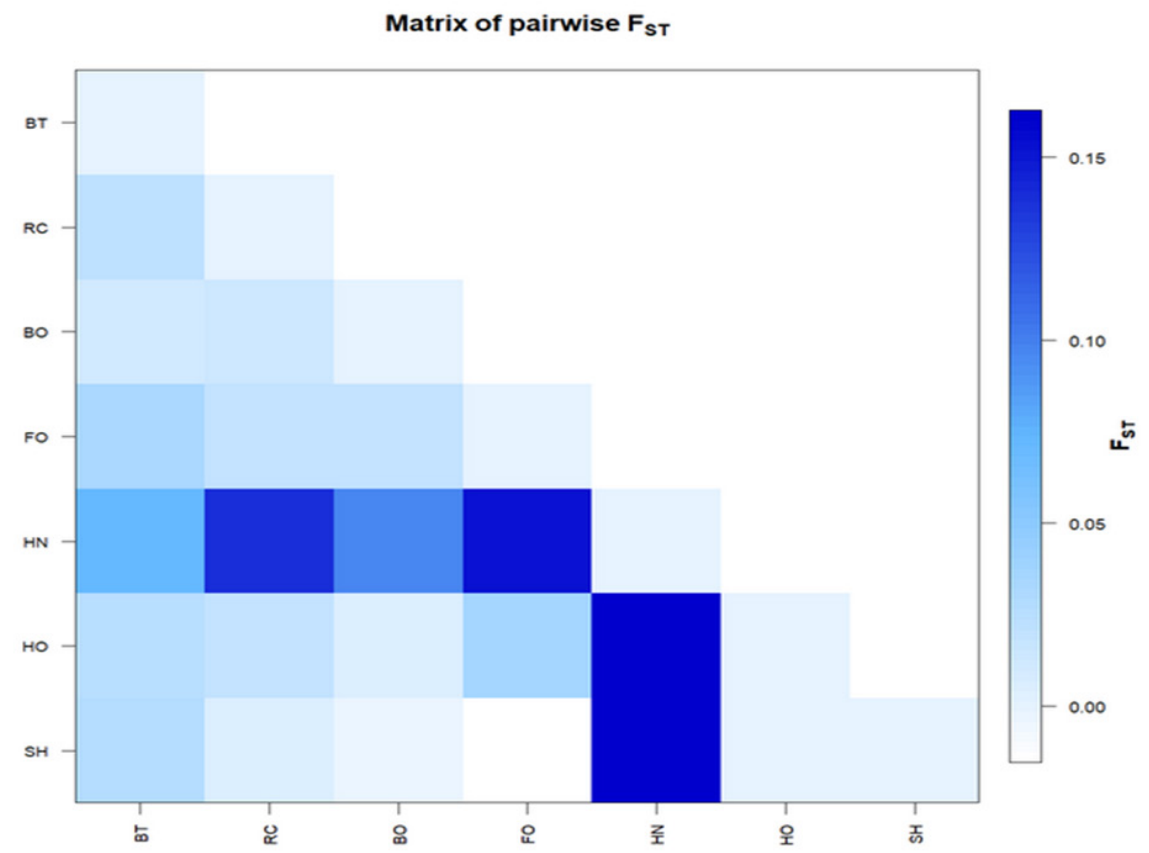

Fig. 3. Representation of calculated $F_{S T}$ values between pairs of populations graph generated by $R$ function: pair $\mathbf{F}_{\mathrm{ST}}$ matrix.r. RC, Bangladesh Red Chittagong; BO, Boran; FO, Fogera; HN, Hanwoo; HO, Horro; $\mathrm{SH}$, Sheko; BT, Bos taurus.

was compared between cattle breeds and the highest $\mathrm{G}_{\mathrm{ST}}$ value was observed between Bangladesh Red Chittagong and Sheko (0.110). The lowest $\mathrm{G}_{\mathrm{ST}}$ value (0.005) was found between Horro, and Boran (Table 5).

\section{Phylogenetic relationships and Median Joining network}

The evolutionary history was inferred by using maximum likelihood method based on Kimura-2 parameter model with bootstrap replications of 1000 and the evolutionary tree inferred from cattle for DRB3. 2 locus sequences are presented in Fig. 4. There was no clear separated cluster among the cattle breeds of this study, and they shared a common node from the constructed tree. It looks that DRB3 alleles might have evolved through multiple lineages. 


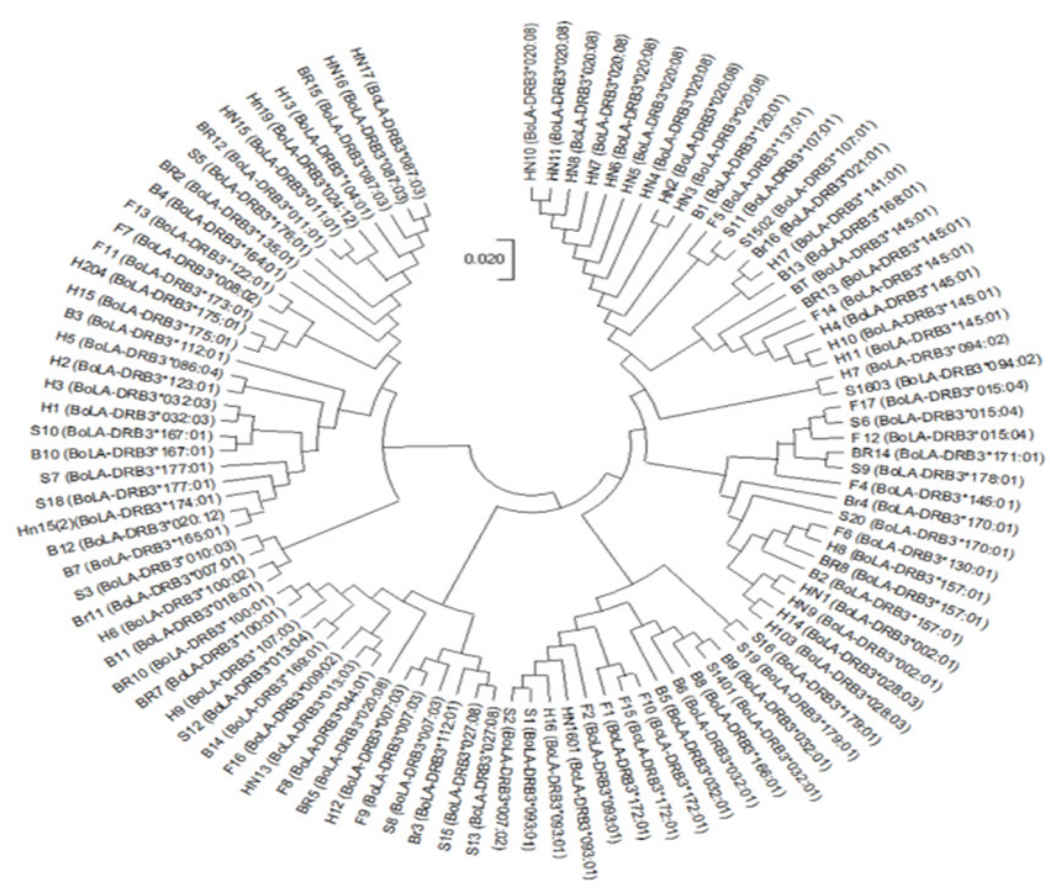

Fig. 4. Phylogenetic Tree. $B$ = Bangladesh Red Chittagong; Br, Boran; F, Fogera; Hn, Hanwoo; H, Horro; S, Sheko; BT, Bos taurus.

\section{DISCUSSION}

The new alleles identified from the sequences of BoLA-DRB3 exon2 locus could function as additional marker specific to either Bos indicus or Bos taurus genotypes [29-33]. The biological response to pathogens and parasitic infection is strongly dependent on the level of genetic diversity at the MHC loci [34,35]. The allele BoLA-DRB3*009:02 was reported to be resistant to BLV [36] and detected in the Hanwoo breed (Table 2). In addition, the highest polymorphic sites and the total number of mutations of the BoLA- DRB3 gene were found in Sheko breed that could be a candidate for the future study of tsetse resistance.

Sequence analysis of the BoLA-DRB3 gene for base substitutions showed a higher rate of non-synonymous substitution (NSS) as compared to synonymous substitution (SS). The ratio of (NSS/SS) was evaluated and the values recorded were more than one for all the breeds. The result suggested that variation at the antigen-binding site $(\mathrm{ABS})$ is under positive selection which could be for the recognition of a wide range of pathogenic agents [37,38]. The higher variability of the gene is highly linked to the regions of peptide binding sites (PBS) by which amino acid residues interacting directly with antigens. Therefore, molecules coded by different alleles have different antigen-binding profiles and again influence the susceptibility to pathogens [38]. Hence, the BoLA-DRB3 gene increased the fitness of the populations to live in pathogenic areas and have a positive impact in animal breeding. The widely reported studies indicated that Zebu cattle had high disease tolerance to tropical infectious diseases like tick born disease and intestinal parasites [39,40]. Therefore, the result of this study shared great insight and calls to the scientific community about the BoLA-DRB3 gene, especially for animal breeders and vaccine designers.

Investigating a population in terms of genetic diversity, researchers used nucleotide and haplotype diversities as common directories [41]. The values of heterozygosity were lower when compared with previous study of Tanzania Shorthorn Zebu, Boran, and Holstein Friesian breeds 
$[30,42]$. The heterozygosity in Japan cattle breeds were higher as reported by previous studies [43] (Ho ranged from 0.905 to 0.921 and He ranged from 0.887 to 0.914 ). Similarly, higher values of He were reported in Poland ranged from 0.920 to 0.927 [44]. The observed heterozygosity was not significantly higher than the expected heterozygosity $(p<0.05)$. Hence, HWE of all the breeds analyzed showed non-significant excess of heterozygotes animals that could reveal over-dominant selection. The result was similar with the recent report conducted to investigate South American Zebu breeds [7].

The results of pairwise $\mathrm{F}_{\mathrm{ST}}$ values indicated low genetic differentiation of the Ethiopian breeds with Asian zebu which confirmed the investigation reported among Asian, African and American breeds [22]. The estimations of negative $F_{\text {ST }}$ value between Sheko and Boran as well as between Sheko and Fogera, suggesting no population sub-division at this locus. Moreover, the genetic differentiation of all the breeds based on $\mathrm{G}_{\mathrm{ST}}$ was small and supported by the previous studies $[7,22,30]$. The little genetic distance inferred from the breeds could be the result of the evolutionary or domestication history of cattle breeds [45].

Fu's $F_{S}$ test [23] which was used to identify neutrality showed that all the breeds were neutral $(p>0.02)$. The result suggested that Ethiopian indigenous cattle breeds and Asian breeds are not significantly differentiated in terms of genetic diversity of the BoLA-DRB3 gene. The estimated negative values of Fu's $F_{S}$ indicate the evidence for an excess number of alleles and could be expected from a recent population expansion or genetic hitchhiking. Whereas, positive values of $\mathrm{F}_{\mathrm{S}}$ deficiency of alleles, as would be expected from a recent population bottleneck. Except for the positive values of $F_{S}$ for Hanwoo we recorded the negative $F_{S}$ values from all the breeds. Ethiopian Sheko breed which is found in the Southern part of the Bench Maji zone was reported to be trypanotolerant as compared to zebu breeds. Due to the higher degree of trypanotolerance of the breed, Ethiopian Sheko cattle are kept in tsetse infested regions [46]. Breeds kept in the pathogenic environments are forced to develop adaptive immunity by the principles of natural selection and diversifications of immune-related genes could happen. Thus, we may have found the higher polymorphic sites and a greater number of total mutations rate in Sheko breed.

We observed a close genetic relationship between the Ethiopian cattle breeds and Asian breeds from the inferred phylogenetic tree and median joining-network tree. The close genetic relationship between Ethiopian cattle and Bangladesh Red Chittagong is consistent with the evidence of all Ethiopian cattle populations shared a higher proportion of Asian zebu ancestry [47-49].

This study confirmed that the MHC II DRB3.2 locus is extremely crucial and may provide baseline information for in-depth understanding and exploitation of MHC gene variation in Ethiopian, cattle populations exposed to an extensive range of pathogenic agents. The alleles we identified from the present populations require further validation to the association of disease susceptibility/resistance. Moreover, the sequence polymorphism of BoLA-DRB3.2 identified from our study should be further confirmed by sequencing more samples.

\section{REFERENCES}

1. Andersson L, Bóhme J, Peterson PA, Rask L. Genomic hybridization of bovine class II major histocompatibility genes: 2. polymorphism of DR genes and linkage disequilibrium in the DQ-DR region. Anim Genet. 1986;17:295-304. https://doi.org/10.1111/j.1365-2052.1986. tb00723.x

2. Groenen AM, Van Der Poel JJ, Dijkhof RJM, Giphart MJ. Cloning of the bovine major histocompatibility complex class II genes. Anim Genet. 1989;20:267-78. https://doi.org/10.1111/ j.1365-2052.1989.tb00867.x 
3. Groenen MAM, van der Poel JJ, Dijkhof RJ, Giphart MJ. The nucleotide sequence of bovine MHC class II DQB and DRB genes. Immunogenetics 1990;31:37-44. https://doi. org/10.1007/BF00702487

4. Bohórquez MD, Ordoñez D, Suárez CF, Vicente B, Vieira C, López-Abán J, et al. Major histocompatibility complex Class II (DRB3) genetic diversity in Spanish Morucha and Colombian Normande cattle compared to taurine and zebu populations. Fron Genet. 2020;10:1293. https://doi.org/10.3389/fgene.2019.01293

5. Phillips KP, Cable J, Mohammed RS, Herdegen-Radwan M, Raubic J, Przesmycka KJ, et al. Immunogenetic novelty confers a selective advantage in host-pathogen coevolution. Proc Natl Acad Sci USA. 2018;115:1552-7. https://doi.org/10.5061/dryad.72262

6. Sigurdardóttir S, Borsch C, Gustafsson K, Andersson L. Cloning and sequence analysis of 14 DRB alleles of the bovine major histocompatibility complex by using the polymerase chain reaction. Anim Genet. 1991;22:199-209. https://doi.org/10.1111/j.1365-2052.1991.tb00670.x

7. Takeshima SN, Corbi-Botto C, Giovambattista G, Aida Y. Genetic diversity of BoLA-DRB3 in South American Zebu cattle populations. BMC Genet. 2018;19:1-13. https://doi. org/10.1186/s12863-018-0618-7

8. Maccari G, Robinson J, Ballingall K, Guethlein LA, Grimholt U, Kaufman J, et al. IPD-MHC 2.0: an improved inter-species database for the study of the major histocompatibility complex. Nucleic Acids Res. 2017;45:860-4. https://doi.org/10.1093/nar/gkw1050

9. Hameed KGA, Grażyna Sender G, Mayntz M. Major histocompatibility complex polymorphism and mastitis resistance: a review. Anim Sci Pap Rep. 2006;24:11-25.

10. Welderufael BG, Løvendahl P, de Koning DJ, Janss LLG, Fikse WF. Genome-wide association study for susceptibility to and recoverability from mastitis in Danish holstein cows. Fron Genet. 2018;9:141. https://doi.org/10.3389/fgene.2018.00141

11. Suprovych TM, Suprovych MP, Koval TV, Karchevska TM, Chepurna VA, Chornyi IO, et al. BoLA-DRB3 gene as a marker of susceptibility and resistance of the Ukrainian blackpied and red-pied dairy breeds to mastitis. Regul Mech Biosyst. 2018;9:363-8. https://doi. org/10.15421/021853

12. Lee BY, Hur, TY, Jung YH, Kim H. Identification of BoLA-DRB3.2 alleles in Korean native cattle (Hanwoo) and Holstein populations using a next generation sequencer. Anim Genet. 2011;43:438-41. https://doi.org/10.1111/j.1365-2052.2011.02264.x

13. Bhuiyan AKFH, Shahjalal M, Islam MN, Rahman AKMA, Keown JF, Van Vleck LD, et al. Characterization, conservation and improvement of Red Chittagong Cattle of Bangladesh. Bangladesh Agric Univ Res Sys Program 2005:13-21.

14. Mekuriaw G, Kebede A. A review on indigenous cattle genetic resources in Ethiopia: adaptation, status and survival. Online J Anim Feed Res. 2015;5:125-37.

15. Van Eijk MJT, Stewart-Haynes JA, Lewin HA. Extensive polymorphism of the BoLA-DRB3 gene distinguished by PCR-RFLP. Anim Genet. 1992;23:483-96. https://doi.org/10.1111/ j.1365-2052.1992.tb00168.x

16. Larkin MA, Blackshields G, Brown NP, Chenna R, McGettigan PA, McWilliam H, et al. Clustal W and Clustal X version 2.0. Bioinforormatics 2007;23:2947-8. https://doi. org/10.1093/bioinformatics/btm404

17. Excoffier L, Lischer HEL. Arlequin suite ver 3.5: a new series of programs to perform population genetics analyses under Linux and Windows. Mol Ecol Res. 2010;10:564-7. https:/doi. org/10.1111/j.1755 0998.2010.02847.x

18. Weir BS, Cockerham CC. Estimating F-statistics for the analysis of population structure. Evolution. 1984;38:1358-70. https://doi.org/10.2307/2408641 
19. Rousset F. Genepop'007: a complete re-implementation of the genepop software for windows and Linux. Mol Ecol Resour. 2008;8:103-6. https://doi.org/10.1111/j.14718286.2007.01931.x

20. Librado P, Rozas J. DnaSP v5: a software for comprehensive analysis of DNA polymorphism data. Bioinformatics. 2009;25:1451-2. https://doi.org/10.1093/bioinformatics/btp187

21. Muhire BM, Varsani A, Martin DP. SDT: a virus classification tool based on pairwise sequence alignment and identity calculation. PLOS ONE 2014;9:e108277. https://doi.org/10.1371/ journal.pone.0108277

22. Peters SO, Hussain T, Adenaike AS, Adeleke MA, De Donato M, Hazzard J, et al. Genetic diversity of bovine major histocompatibility complex class II DRB3 locus in cattle breeds from Asia compared to those from Africa and America. J Genom. 2018;6:88-97. https://doi. org/10.7150/jgen.26491

23. Tajima F. Statistical method for testing the neutral mutation hypothesis by DNA polymorphism. Genetics. 1989;123:585-95. https://doi.org/10.1093/genetics/123.3.585

24. Fu YX. Statistical tests of neutrality of mutations against population growth hitchhiking, and background selection. Genetics. 1997;147:915-25. https://doi.org/10.1093/genetics/147.2.915

25. Kimura M. A simple method for estimating evolutionary rate of base substitutions through comparative studies of nucleotide sequences. J Mol Evol. 1980;16:111-20. https://doi. org/10.1007/BF01731581

26. Kumar S, Stecher G, Li M, Knyaz C, Tamura K. MEGA X: molecular evolutionary genetics analysis across computing platforms. Mol Biol Evol. 2018;35:1547-9. https://doi. org/10.1093/molbev/msy096

27. Nei M, Kumar S. Molecular evolution and phylogenetics. New York, NY: Oxford University Press; 2000.

28. Bandelt H, Forster P, Röhl A. Median-joining networks for inferring intraspecific phylogenies. Mol Biol Evol. 1999;16:37-48. https://doi.org/10.1093/oxfordjournals.molbev.a026036

29. Takeshima SN, Miyasaka T, Matsumoto Y, Xue G, de la Barra Diaz V, Rogberg Muñoz A, et al. Assessment of biodiversity in Chilean cattle using the distribution of major histocompatibility complex class II BoLA DRB3 allele. Tissue Antigens. 2015;85:35-44. https://doi. org $/ 10.1111 / \tan .12481$

30. Inick DL, Msalya G, Kipanyula M, Karimuribo E, Chenyambuga S. Polymorphisms of BoLA-DRB 3.2 gene and associated genetic relationships among four strains of Tanzania shorthorn zebu cattle. J Anim Breed Genom. 2018;2:245-56. https://doi.org/10.12972/jabng.201800XX

31. Takeshima S, Nakai Y, Ohta M, Aida Y. Short communication: characterization of DRB3 alleles in the $\mathrm{MHC}$ of Japanese shorthorn cattle by polymerase chain reaction-sequence-based typing. J Dairy Sci. 2002;85:1630-2. https://doi.org/10.3168/jds.S0022-0302(02)74234-3

32. Nassiry MR, Shahroodi FE, Mosafer J, Mohammadi A, Manshad E, Ghazanfari S, et al. Analysis and frequency of bovine lymphocyte antigen (BoLA-DRB3) alleles in Iranian Holstein cattle. Russ J Genet. 2005;41:817-22. https://doi.org/10.1134/S1022795409020100

33. Behl JD, Verma NK, Tyagi N, Mishra P, Behl R, Joshi BK. The major histocompatibility complex in bovines: a review. Int Sch Res Notices. 2012;2012:1-12. https://doi. org10.5402/2012/872710

34. Hedrick PW. Genetics of complex polymorphisms: parasites and the maintenance of the major histocompatibility complex variation. In: Singh RS, Krimpas CB, editors. Evolutionary genetics from molecules to morphology. Cambridge, UK: Cambridge University Press; 2000. p. 204-34.

35. Ojong BW, Saccà E, Bessong P, Piasentier E. Prevalence of bovine dermatophilosis and dis- 
ease-associated alleles in zebu Goudali cattle and their Italian Simmental crosses ranching in the western highland plateau savannah of Cameroon. Trop Anim Health Prod. 2016;48:132935. https://doi.org/10.1007/s11250-016-1097-3

36. Takeshima SN, Ohno A, Aida Y. Bovine leukemia virus proviral load is more strongly associated with bovine major histocompatibility complex class II DRB3 polymorphism than with DQA1 polymorphism in Holstein cow in Japan. Retrovirology. 2019;16:1-6. https://doi. org/10.1186/s12977-019-0476-Z

37. Hughes AL, Yeager M. Natural selection at major histocompatibility complex loci of vertebrates. Annu Rev Genet. 1998;32:415-35. https://doi.org/10.1146/annurev.genet.32.1.415

38. Radwan J, Babik W, Kaufman J, Lenz TL, Winternitz J. Advances in the evolutionary understanding of MHC polymorphism. Trends Genet. 2020;36:298-311. https://doi.org/10.1016/ j.tig.2020.01.008

39. Porto Neto LR, Jonsson NN, D’Occhio MJ, Barendse W. Molecular genetic approaches for identifying the basis of variation in resistance to tick infestation in cattle. Vet Parasitol. 2011;180:165-72. https://doi.org/10.1016/j.vetpar.2011.05.048

40. Magee DA, MacHugh DE, Edwards CJ. Interrogation of modern and ancient genomes reveals the complex domestic history of cattle. Anin Front. 2014;4:7-22. https://doi.org/10.2527/ af.2014-0017

41. Adefnwa MA, Peters SO, Agaviezor BO, Wheto M, Adekoya KO, Okpeku M, et al. Identification of single nucleotide polymorphisms in the agouti signaling protein (ASIP) gene in some goat breeds in tropical and temperate climates. Mol Biol Rep. 2013;40:4447-57. https://doi. org/10.1007/s11033-013-2535-1

42. Msalya G, Kim ES, Laisser ELK, Kipanyula MJ, Karimuribo ED, Kusiluka LJM, et al. Determination of genetic structure and signatures of selection in three strains of Tanzania Shorthorn Zebu, Boran and Friesian Cattle by genome-wide SNP analyses. PLOS ONE 2017;12:e0171088. https://doi.org/10.1371/journal.pone.0171088

43. Takeshima S, Saitou N, Morita M, Inoko H, Aida Y. The diversity of bovine MHC class II DRB3 genes in Japanese Black, Japanese Shorthorn, Jersey and Holstein cattle in Japan. Gene. 2003;316:111-8. https://doi.org/10.1016/s0378-1119(03)00744-3

44. Jolanta O, Piotr U, Grażyna S, Adrianna P, Marek L. Frequency of BoLA-DRB3 alleles in Polish Holstein Friesian cattle. Anim Sci Pap Rep. 2012;30:91-101.

45. Bradley DG, Loftus RT, Cunningham P, MacHugh DE. Genetics and domestic cattle origins. Evol Anthropol. 1998;6:79-86. https://doi.org/10.1002/(SICI)15206505(1998)6:3<79::AID-EVAN2>3.0.CO;2-R

46. Bahbahani H, Salim B, Almathen F, Al Enezi F, Mwacharo JM, Hanotte O. Signatures of positive selection in African Butana and Kenana dairy zebu cattle. PLOS ONE. 2018;13:e0190446. https://doi.org/10.1371/journal.pone.0190446

47. Edea Z, Dadi H, Kim SW, Dessie T, Lee T, Kim H, et al. Genetic diversity, population structure and relationships in indigenous cattle populations of Ethiopia and Korean Hanwoo breeds using SNP markers. Front Genet. 2013;4:35. https://doi.org/10.3389/fgene.2013.00035

48. Takeshima SN, Ikegami M, Morita M, Nakai Y, Aida Y. Identification of new cattle BoLA-DRB3 alleles by sequence-based typing. Immunogenetics. 2001;53:74-81. https://doi. org/10.1007/s002510000293

49. Jeong HJ, Bhuiyan MSA, Lee JS, Yu SL, Sang BC, Yoon D. Characterization of BoLA-DRB3.2 alleles in Hanwoo (Korean cattle) by sequence based typing (SBT). Asian Australas J Anim Sci. 2007;20:1791-7. https://doi.org/10.5713/ajas.2007.1791 